juice was diverted to the outside, and increased when either pancreatic juice or 'Phosphalugel' was injected into the duodenum, suggests that pancreatic secretion into the duodenum may, by elevating duodenal $p \mathrm{H}$, release the duodenal gastrin described recently by Emås ${ }^{4}$ and this release of gastrin is inhibited by acid ${ }^{5}$.

George Stacher

First Surgical Clinie,

Vienna, Austria.

First Surgical Clinic,

J. Pang Tay Tea

University of Lyon,

Lyon, France.

Department of Surgery,

University of Washington School of Medicine,

Seattle, Washington.

' Greenlee, H. B., Nelsen, 'T. S., and Dragstedt, L. R., Surg. Forum, 10, 161 (1959).

${ }^{3}$ McIlrath, D. F., Kennedy, J. A., and Hallenbeck, G. A., Amer. J. Digestive Dis., 8, 623 (1963).

White, T. T., and Magee, D. F., Surg. Gynec. Obst., 114, 463 (1962).

4 Emås, S., and Fyró, B., Acta Physiol. Scand., 63, 358 (1965).

Sircus, W., Quart. J. Exp. Physiol., 43, 114 (1958).

\section{Isolation of Formaldehyde from Betaine, Dimethylglycine and Sarcosine}

Handler et al. 1 have observed an increased uptake of oxygen and a positive colour test for formaldehyde when dimethylglycine and sarcosine are incubated with a washed liver sediment. Mackenzie et $a l .{ }^{2}$ found that formaldehyde can be isolated as the dimedone derivative after incubation of dimethylglycine or sarcosine with liver homogenates. When choline and betaine were incubated with liver homogenates, formaldehyde was not isolated.

Formaldehyde was demonstrated as an intermediate of betaine, dimethylglycine or sarcosine oxidation ${ }^{3}$. By using a trapping agent, formaldehyde can be isolated as the dimedone derivative when bacterial intact cells are incubated with betaine, dimethylglycine or sarcosine (Table 1).

\begin{tabular}{|c|c|c|}
\hline Substrate & $\begin{array}{c}0.1 \text { molar potassium } \\
\text { phosphate buffer, } p H \quad 7.4\end{array}$ & $\begin{array}{l}3 \text { per cent } \\
\text { sodium chloride }\end{array}$ \\
\hline $\begin{array}{l}\text { Betaine } \\
\text { Dimethylglycine } \\
\text { Sarcosine }\end{array}$ & $\begin{array}{l}3 \cdot 8 \\
1 \cdot 5 \\
4 \cdot 3\end{array}$ & $\begin{array}{l}4 \cdot 6 \\
3 \cdot 1 \\
5 \cdot 2\end{array}$ \\
\hline
\end{tabular}

The organism Achromobacter cholinophagum is grown on the medium ${ }^{4}$ reported previously and betaine is used at a concentration of 0.5 per cent. $0.5 \mathrm{~g}$ of substrate is incubated for $30 \mathrm{~min}$ at $30^{\circ} \mathrm{C}$ on a shaker with $0.2 \mathrm{~g}$ of semicarbazide hydrochloride and $0.4 \mathrm{~g}$ of intact cells. The total volume of the incubation mixture is $100 \mathrm{ml}$. The yields of formaldehyde are corrected from the endogenous activity and expressed as $\mathrm{mg}$ of the dimedon derivative isolated. The purified formaldemethone has the same melting point $\left(188^{\circ} \mathrm{C}\right)$ as the authentic substance.

It is apparent that three methyl groups of betaine are converted to formaldehyde by the isolated marine bactorium ${ }^{4}$

I thank Dr. D. R. Idler for advice during the course of this work.

\section{H. S. SHIEH}

Halifax Laboratory,

Fisheries Research Board of Canada,

Halifax, Nova Scotia, Canada.

1 Handler, P., Bernheim, M. L. C., and Klein, J. R., J. Biol. Chem., 138, 211 (1941).

2 Mackenzie, C. G., Johnston, J. M., and Frisell, W. R., J. Biol. Chem, 208,

${ }^{3}$ Shieh, H. S., Canad. J. Microbiol.,11, 375 (1965).

- Shieh, H. S., Canad. J. Microbiol., 10, 837 (1964).

\section{Electron Microscopic Investigation of the Shape of Fibrinogen Nodules: a Model for Certain Proteins}

Previous electron microscopic examinations with shadow casting revealed that fibrinogen consists of a beadlike sequence of between three and five nodules. These nodules are supposed to have a spherical appearance ${ }^{1-8}$, and to be between $30 \AA$ and $220 \AA^{1-9}$. Nodules of human fibrinogen derived from native blood were measured in two different directions after shadow casting and a difference of up to 20 per cent was noted in one of the nodules. It was therefore presumed that the configuration of the particles did not fully coincide with that of a spherule ${ }^{9}$. This communication reports investigations carried out on purified beef fibrinogen with the view of determining its form more precisely by the uso of negative staining techniques.

(1) A small drop of an aqueous solution of purified beef fibrinogen $(6 \mathrm{mg} / \mathrm{ml}$.) was placed on the surface of 1 per cent phosphotungstic acid (the $p \mathrm{H}$ was brought to 6.0 by addition of normal sodium hydroxide). Fibrinogen was spread on the sodium phosphotungstate surface and was then picked up by gently touching the surface with a specimen grid coated with 'Formvar'. Any excess phosphotungstic acid was blotted with filter papor.

(2) A drop of purified beef fibrinogen solution was applied to a specimen grid coated with 'Formvar' and excess fluid was blotted. A drop of sodium phospho. tungstate was then added and blotted.

Under the electron microscope the particles of fibrinogen prepared in either of theso ways showed considerable variation in size, in shape, and also in the pattern in which they were arranged (Fig. 1).

A comparison of the electron microscope pictures of fibrinogen particles with a series of crystalloid forms revealed that the fibrinogen nodules are related to a pentagon-dodecahedron. Depending on the position of the three main axes of the dodecahedron, which are of different lengths, the particles appear to have various shapes, sizes and patterns (Fig. 2). A construction table of thirteen different views of a pentagonal dodecahedron in parallel projections ${ }^{11}$ led to the identification of about 70 per cent of the observed fibrinogen particles as dodeca. hedrons (Fig. 2). Dodecahedrons could also be traced in thin sections of fibrin fibres fixed in osmium tetroxide and embedded in methacrylate and 'Vestopal W'. The external diameter of the dodecahedral shaped fibrinogen nodules was about $230 \AA$. Work is in progress to determine the exact lengths of the different axes of the fibrinogen nodules, which is a steric problem ${ }^{10}$.

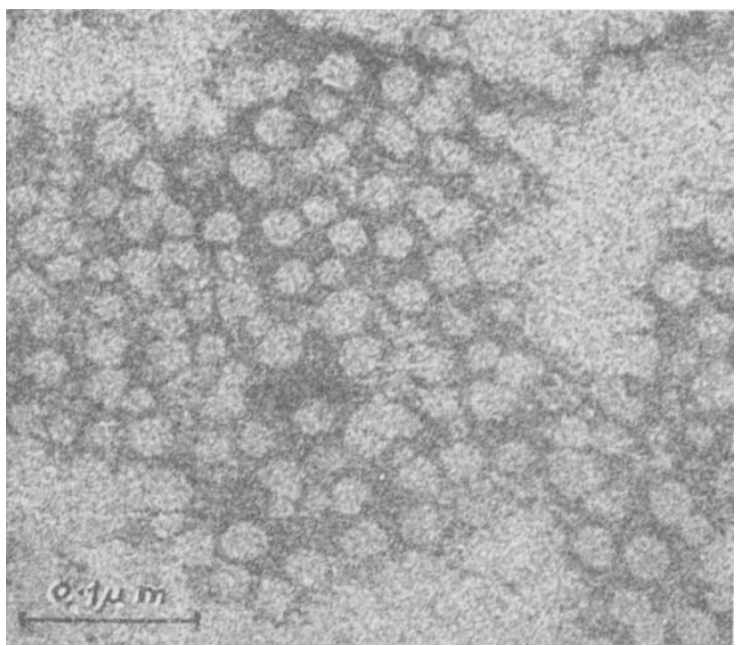

Fig. 1. Bovine fibrinogen negatively stained with sodium phosphotungFig. 1. Bovine ibrinogen negatively stained wedral shape. ( $\times c .172,500$.) 